\title{
Pathogenic and Therapeutic Role of MicroRNAs in Glioblastoma Multiforme
}

\author{
Seyedeh Maliheh Babazadeh ${ }^{1}$, Mohammad Reza Zolfaghary ${ }^{1^{*}}$, Sadegh Shirian², Amir Ghaemi ${ }^{{ }^{*}}$ \\ ${ }^{1}$ Department of Microbiology, Qom Branch, Islamic Azad University, Qom, Iran \\ ${ }^{2}$ Department of Pathology, Faculty of Veterinary Medicine, Shahrekord University, Shahrekord, Iran \\ ${ }^{3}$ Department of Influenza and other Respiratory Viruses, Pasteur Institute of Iran, Tehran, Iran
}

\section{ABSTRACT}

Introduction: Glioblastoma multiforme (GBM) is a severe type of brain tumors with very poor prognosis and a median survival time of about 15 months. To identify new biomarkers and therapeutic approaches, novel methods are crucial to treat GBM, based on the biological and molecular nature of these tumors. Recently, microRNAs (miRNAs) have been extensively used with the aim of developing accurate molecular therapies, due to their emerging role in the regulation of cancer-related genes. miRNAs, a class of small non-coding RNA species, have vital roles across various biological processes, which may serve as diagnostic and prognostic tools in GBM. Conclusion: This review indicated that miRNAs signatures could be used for developing new molecular therapies to enhance the survival of GBM patients. On the other hand, miRNAs regulate a wide range of cellular functions, allowing them to modulate many pathways critical to GBM progression, including proliferation, cell death, metastasis, angiogenesis, and drug resistance.

*Corresponding Authors: Mohammad Reza Zolfaghary, Amir Ghaemi

E-mail:ammhsardar@gmail.com,ghaem_amir@yahoo.com

Key words:

1. Glioblastoma

2. MicroRNAs

3. Cell Death 


\title{
نقش پاتوزنيك و درمانى ريز RNA ها در گَليوبلاستوما مولتىفرم
}

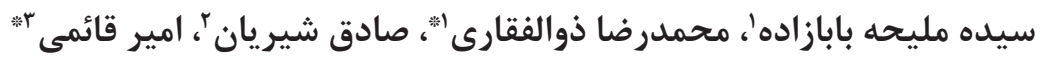 \\ اتروه ميكروب شناسى، واحد قم، دانشخاه آزاد اسلامى، قم، ايران

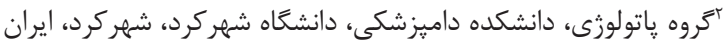 \\ "َّروه آنفلوانزاو ويروس هاى تنفسى شايع، انستيتو پاستور ايران، تهران، ايران
}

\section{اطلاعات مقاله:}

\section{جـ}

مقدمه: گَليوبلاستوما مولتىفرم يك نوع شديدى از تومور مغزى با ريشآثآى بسيار ضعيف و مدت زمان

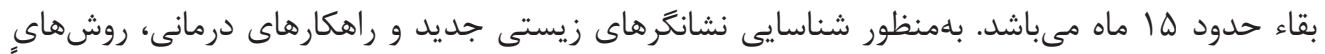

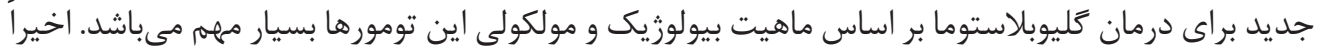

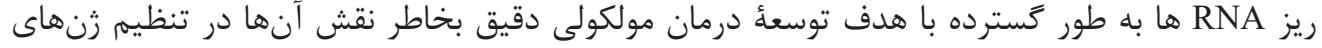

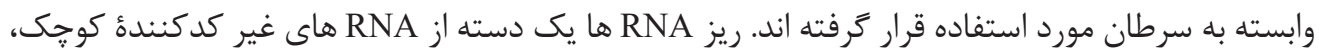

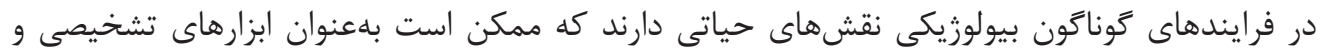

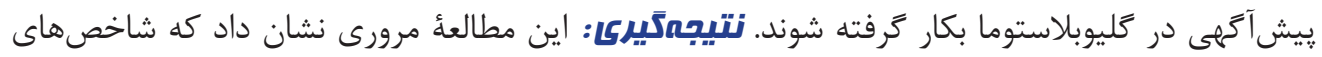

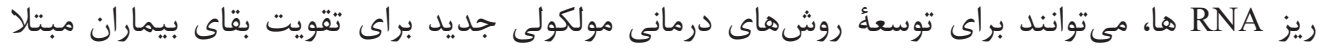

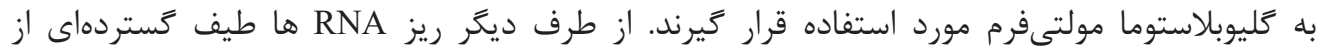

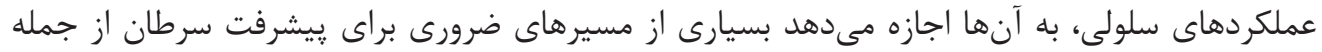

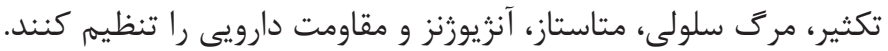

كليد وازهها:

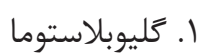

ها RNA ris

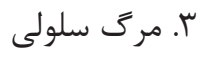

$$
\text { * نويسند }
$$

آدرس الكترونيكى: ammhsardar@gmail.com,ghaem_amir@yahoo.com 


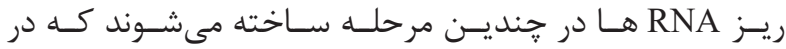

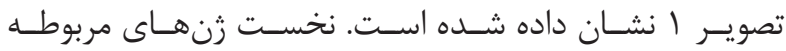

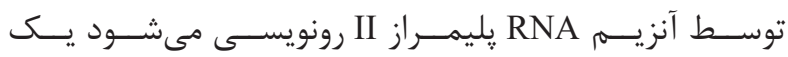

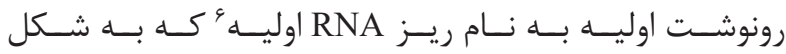

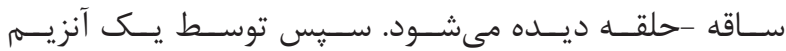

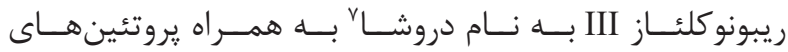

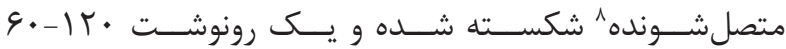

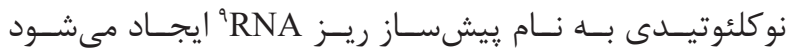

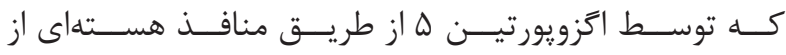

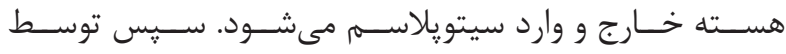

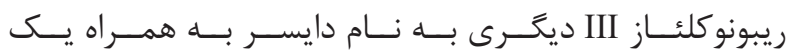

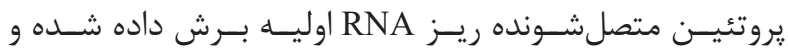

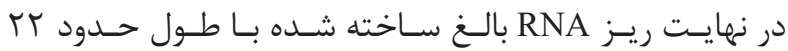

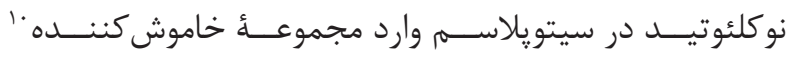

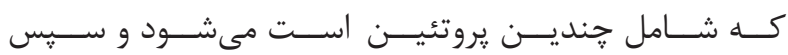

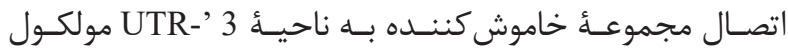

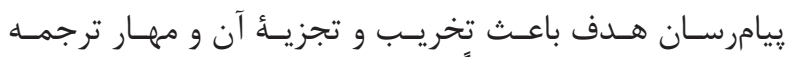

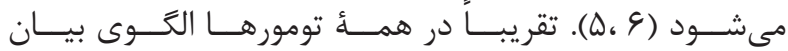

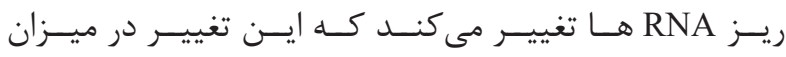

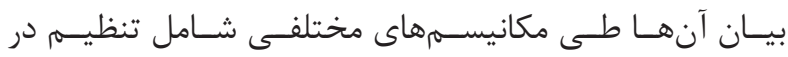

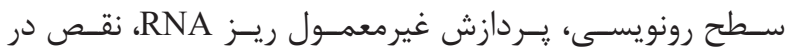

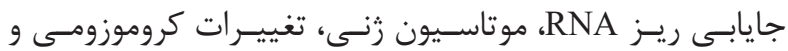

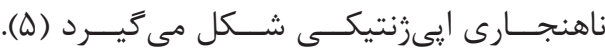

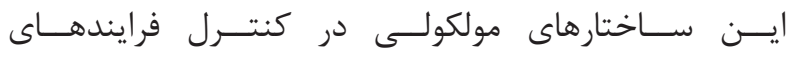

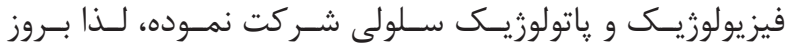

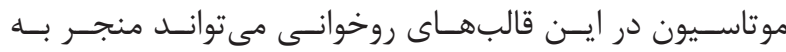

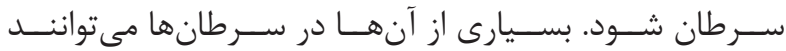

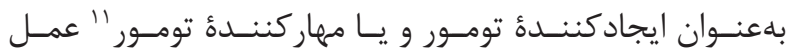

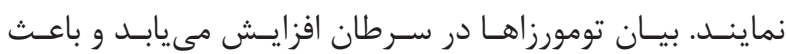

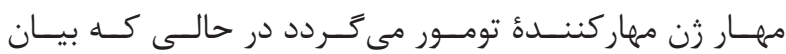

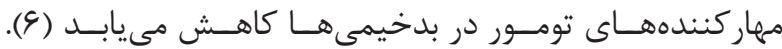

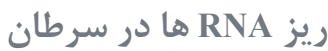

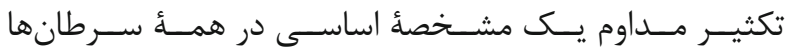

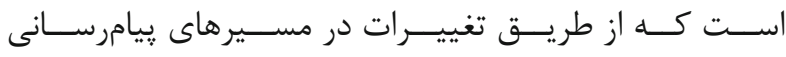

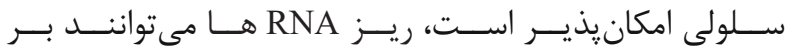

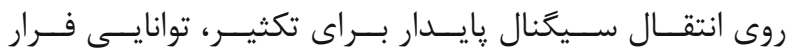

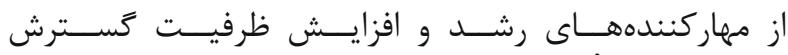

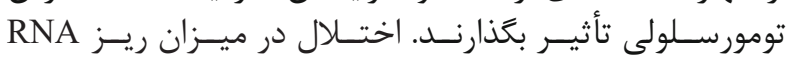

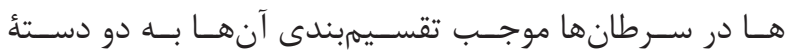

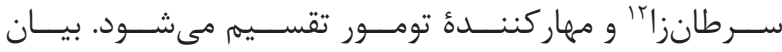

${ }^{1}$ Glioblastoma multiforme

${ }^{2}$ Blood brain barrier

${ }^{3}$ MicroRNAs

${ }^{4}$ Messenger RNA

${ }^{5}$ Hematopoiesis

${ }^{6}$ Primary miRNA
حَليوبلاستوما

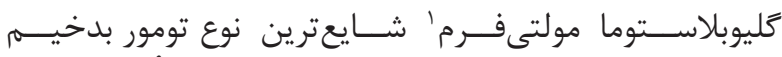

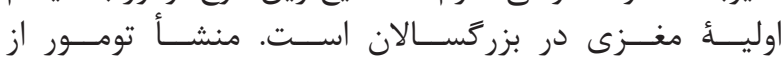

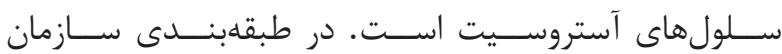

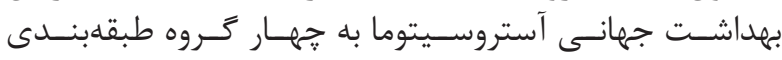

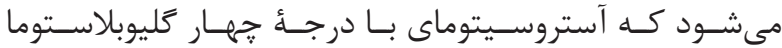

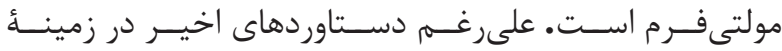

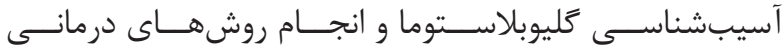

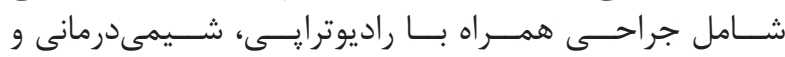

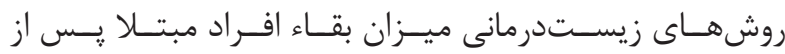

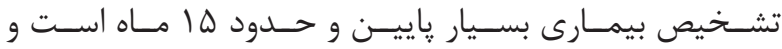

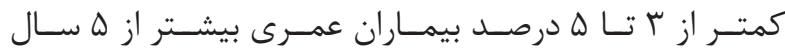

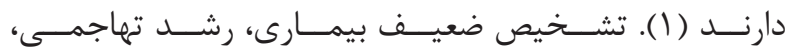

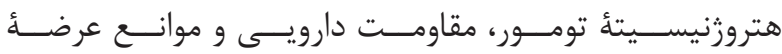

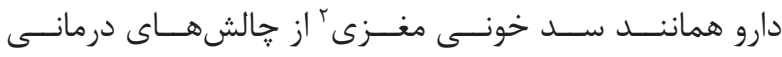

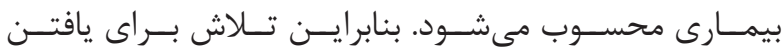

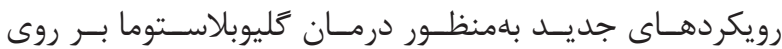

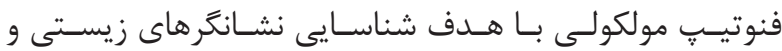

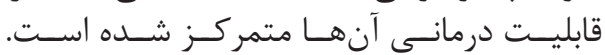

ميكرو ريبونوكلئيك اسيدها

\section{كليات ساختارى و نقش زيستى}

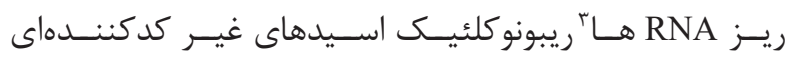

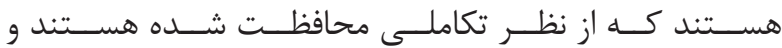

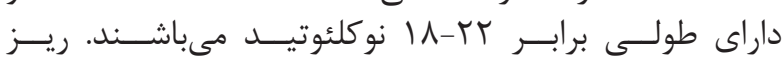

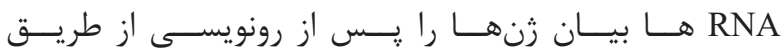

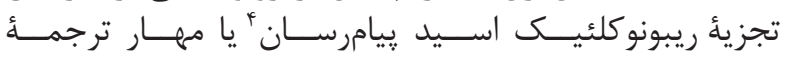

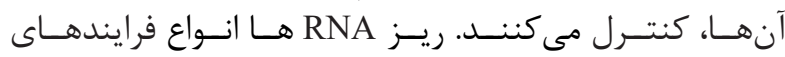

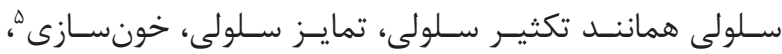

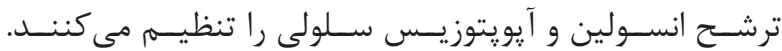

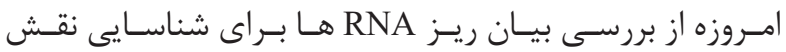

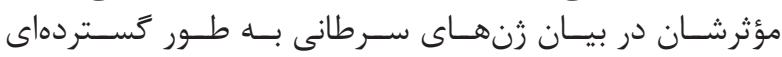

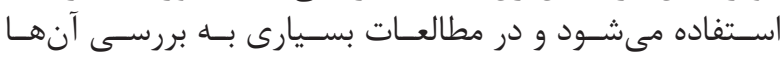

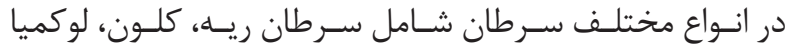

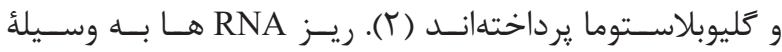

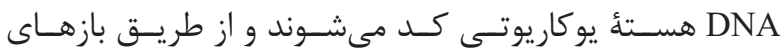

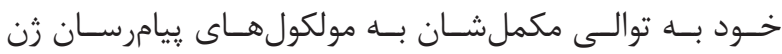

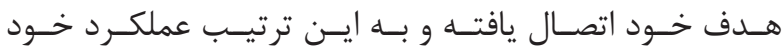

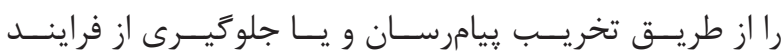

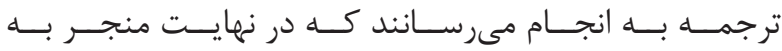

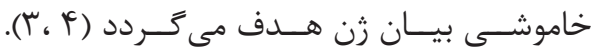

\footnotetext{
${ }^{7}$ Drosha

${ }^{8}$ DGR8

${ }^{9}$ Precursor miRNA

${ }^{10}$ RNA induced silencing complex

${ }^{11}$ Tumor suppressor

${ }^{12}$ Oncogene
} 


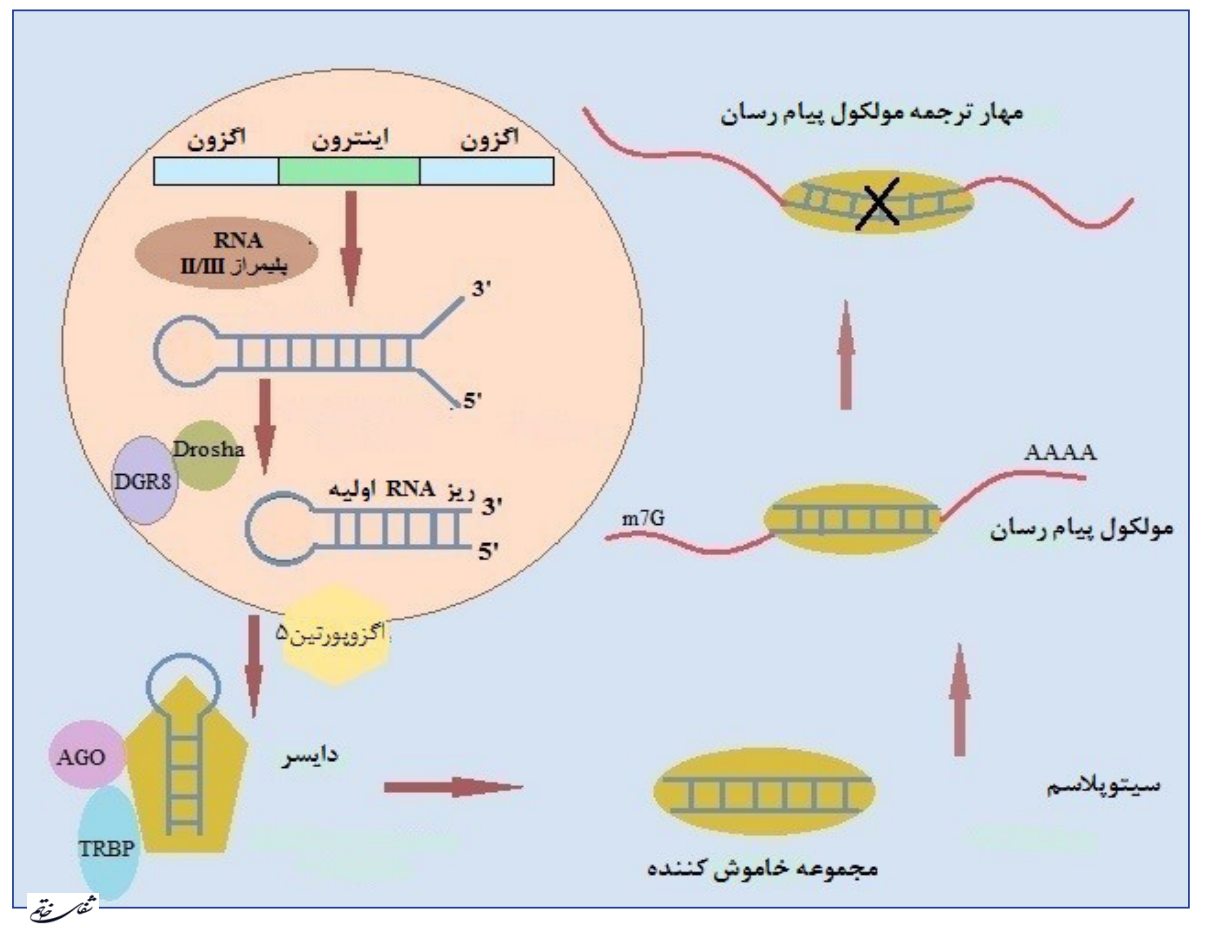

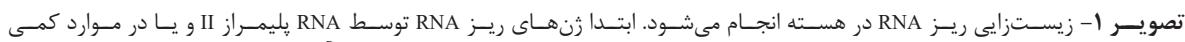

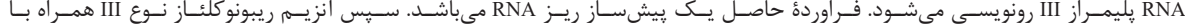

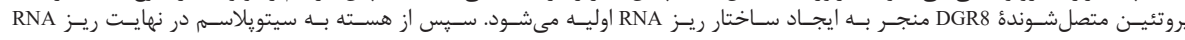

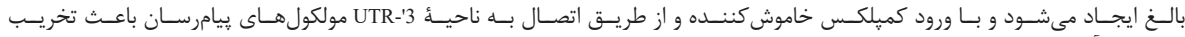

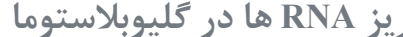

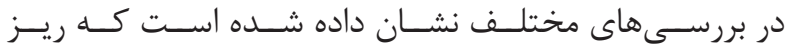

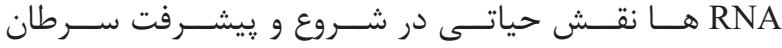

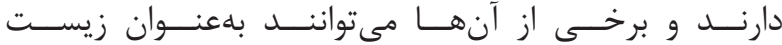

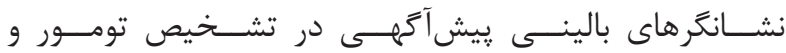

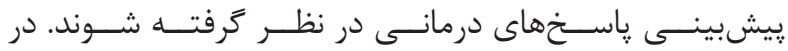

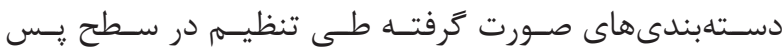

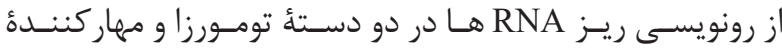

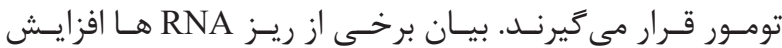

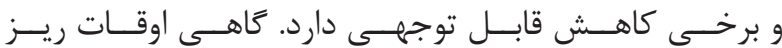

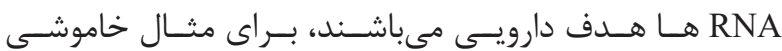

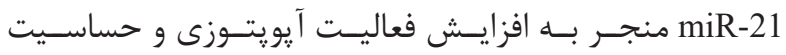

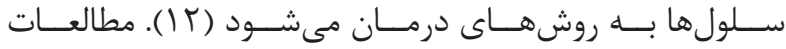

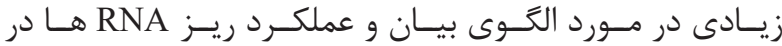

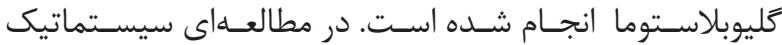

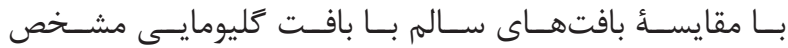

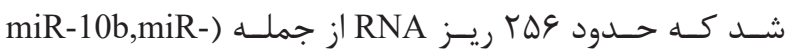

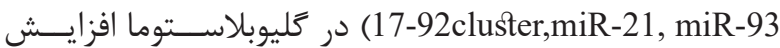

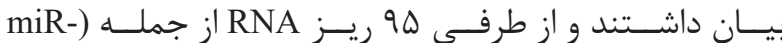

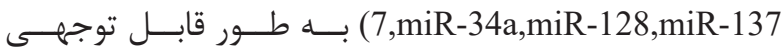

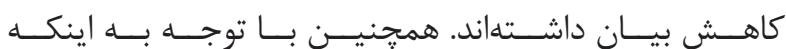

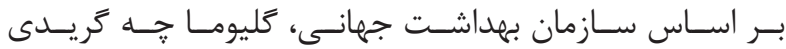

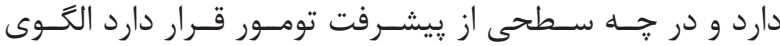

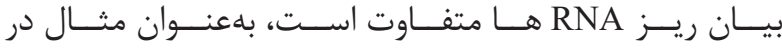

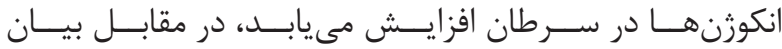

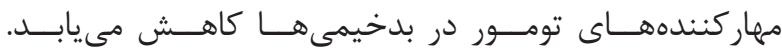

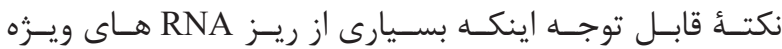

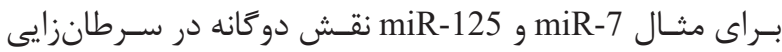

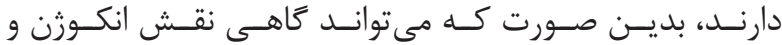

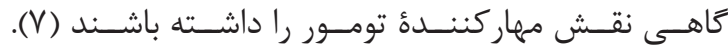

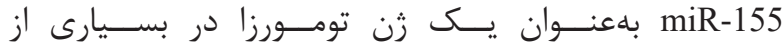

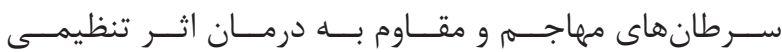

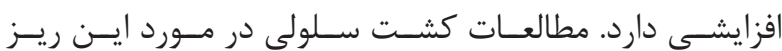

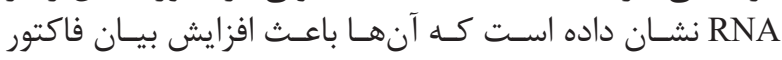

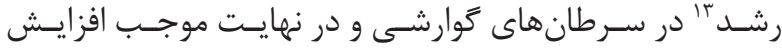

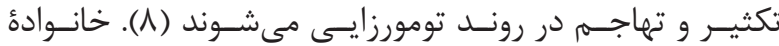

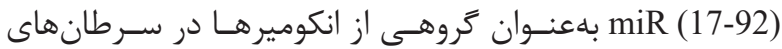

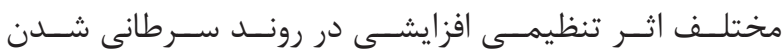

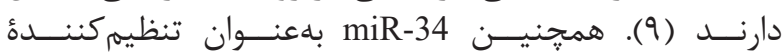

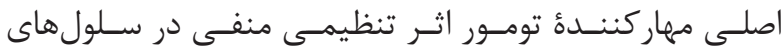

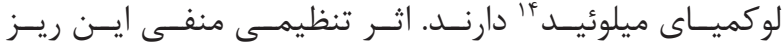

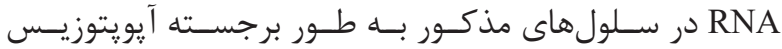

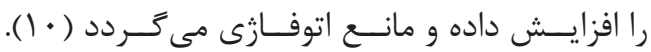

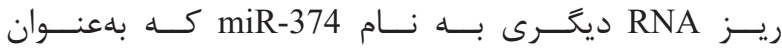

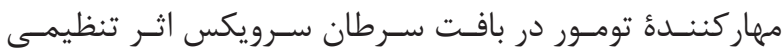

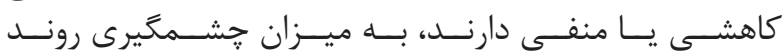

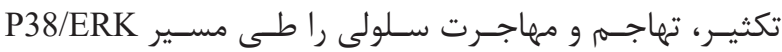

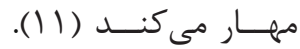




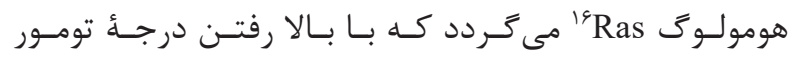

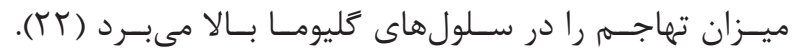

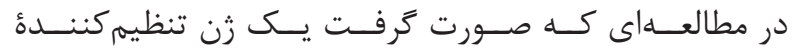

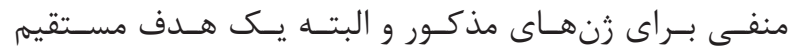

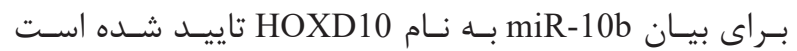

(Y I , YQ

miR 17 92 17 مجموعة

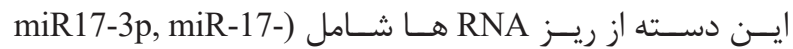
(5p miR-18a, miR-19a, miR-19b, miR-20a, miR-92a

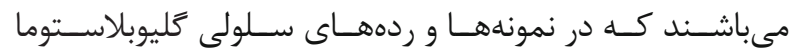

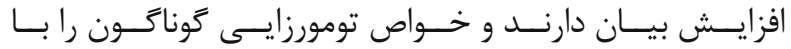

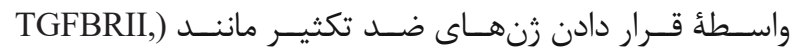

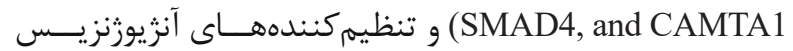

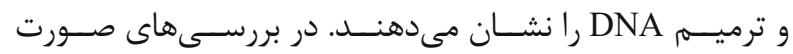

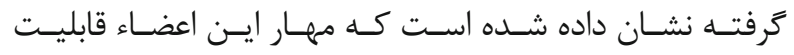

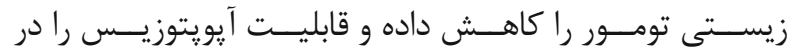

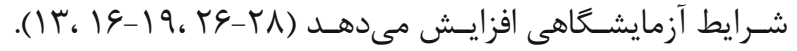

miR-21

طـى بررسـىهاى صـورت كرفتـه نشـان داده شـده اسـت كـهـ

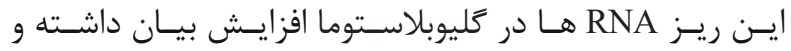

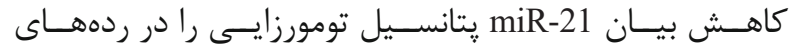

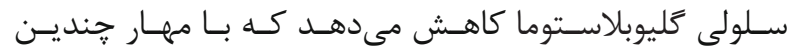

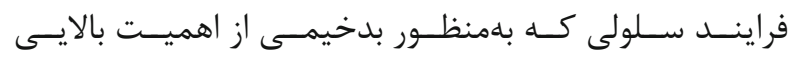

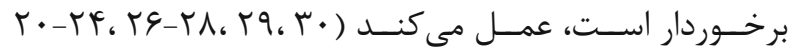

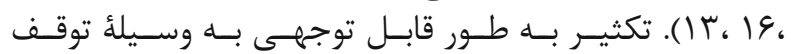

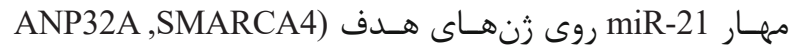

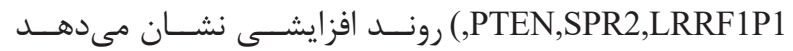

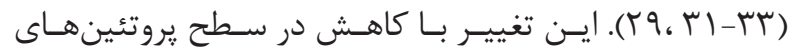

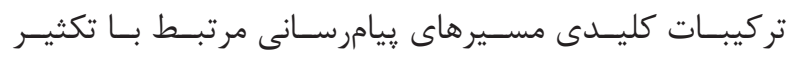

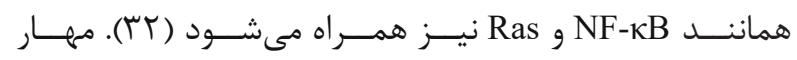

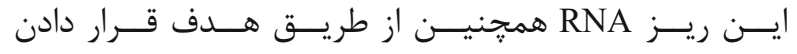

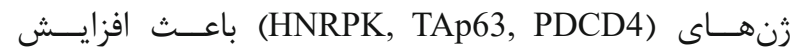

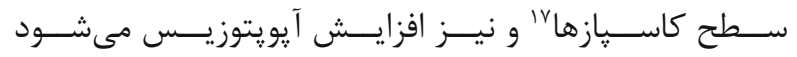

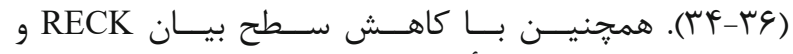
TIMP3

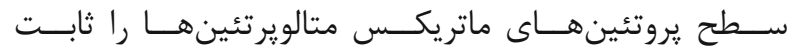

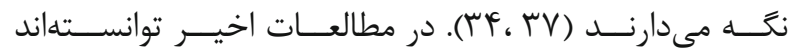

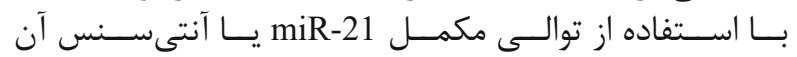

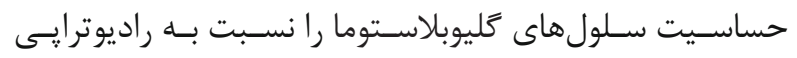

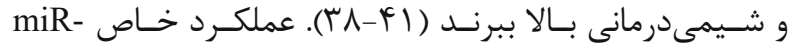

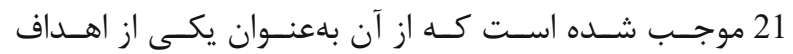

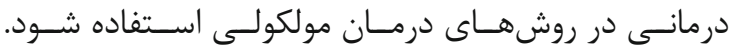

miR-221/miR-222

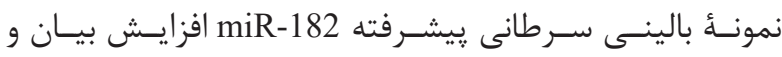

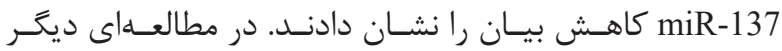

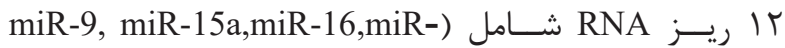
17,miR19a,miR-20a,miR-21,miR-25, miR-28, miRكــه افزايـش بيـان داشـتـند و دو (130b,miR-140,miR-210

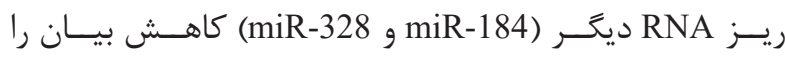

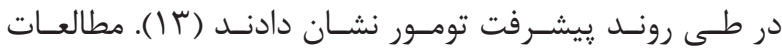

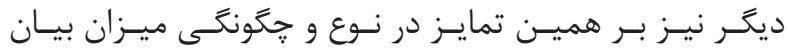

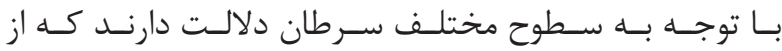

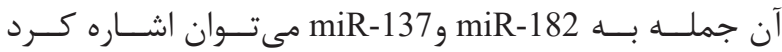

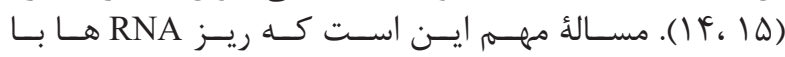

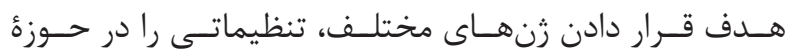

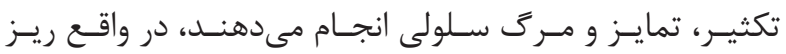

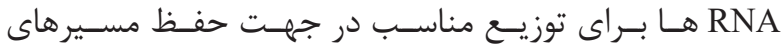

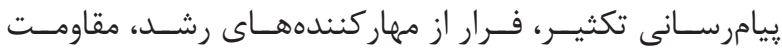

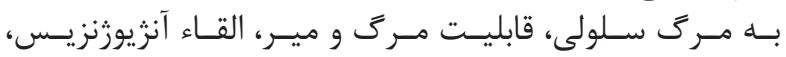

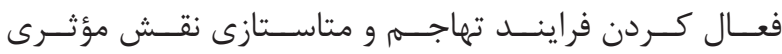

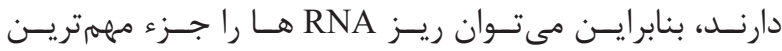

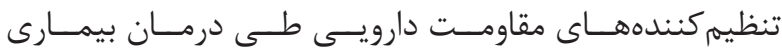

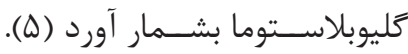

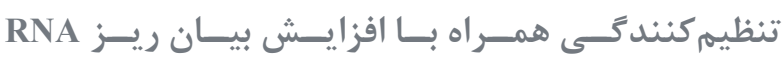

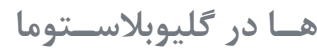

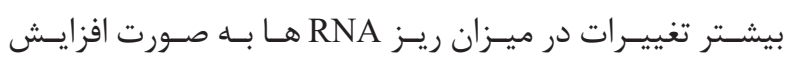

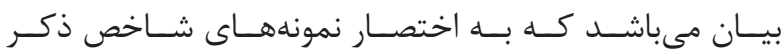

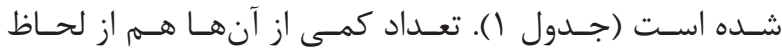

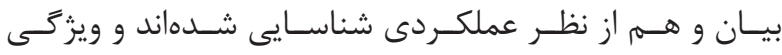

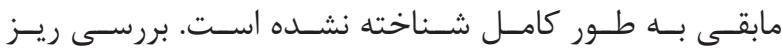

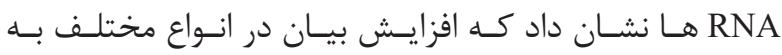

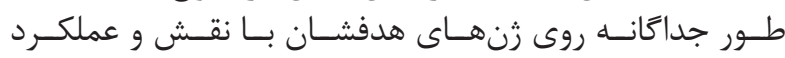

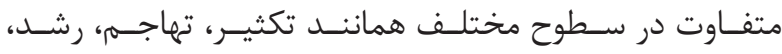

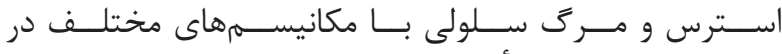

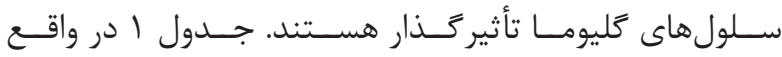

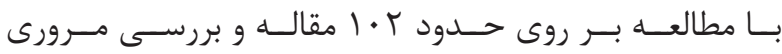

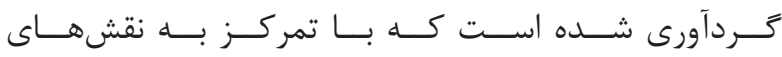

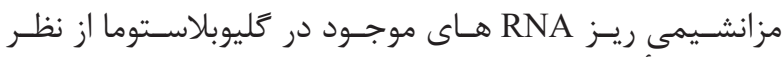

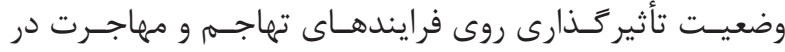

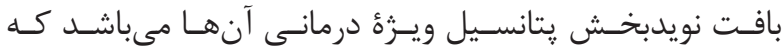

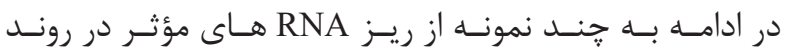

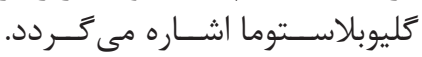
miR-10b

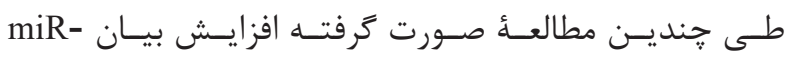

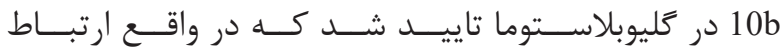

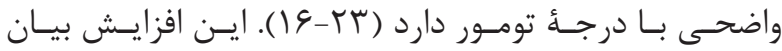

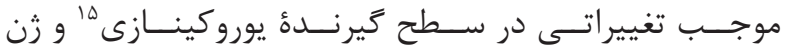

\footnotetext{
${ }^{15}$ Urokinase receptor

${ }^{16}$ Ras is a family of related proteins

${ }^{17}$ Caspase
} 
جدول ا- بيان ريز RNA هاى افزايشى.

\begin{tabular}{|c|c|c|c|}
\hline ريز RNA & 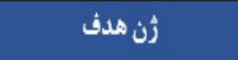 & نقش عملكردى وقتى كه (: أزٔايش بيان دارند با: كاهش بيان دارند & 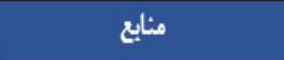 \\
\hline Hsa-mir-9 & CAMTA1 & 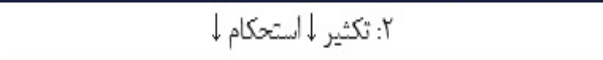 & $\left(I V_{C} Y Y\right)$ \\
\hline Hsa-mir-10 & HOXD10 & ا : تهاجم † ז: تهاجم ل & $(Y 1-Y Q)$ \\
\hline Hsa-mir-15 & CCNE1 & 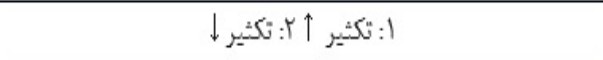 & $\left(M_{6}, Y_{G}, Y M_{6}, M_{G}, F 9\right)$ \\
\hline Hsa-mir-17 & $\begin{array}{c}\text { POLD2, TGFB-RIIb, } \\
\text { CTGF, CAMTA1 }\end{array}$ & 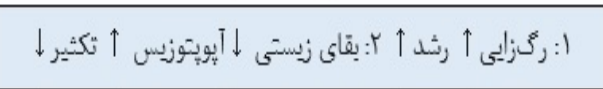 & $\left(M_{c} Y+-Y Q_{c} F \varphi\right)$ \\
\hline Hsa-mir-18 & Smad4, CTGF & 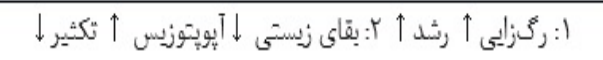 & $\left(Y F_{6}, Y \Delta_{6} Y \varphi\right)$ \\
\hline Hsa-mir-20 & TGF $\beta$-RIIb, CTGF & 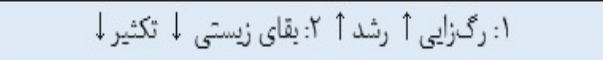 & $\left(Y+-Y_{6}, Y F_{6}, Y G\right)$ \\
\hline Hsa-mir-21 & $\begin{array}{c}\text { RECKd, TIMP3d, } \\
\text { APAF1, ANP32Ad, } \\
\text { SMARCA4, Caspases, } \\
\text { PTEN, Cdc25A, } \\
\text { HNRPK, TAp63, } \\
\text { Spry2d, LRRFIP1, } \\
\text { PDCD }\end{array}$ & 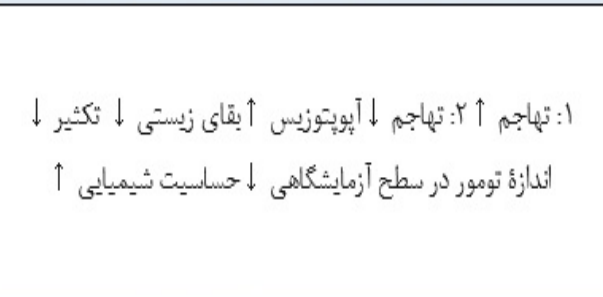 & 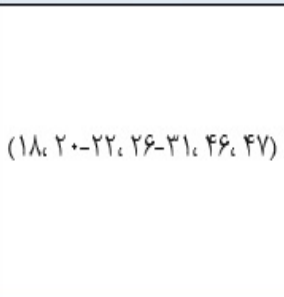 \\
\hline Hsa-mir-25 & $\mathrm{Mdm} 2, \mathrm{TSC} 1$ & 1: أندازٔة تومور در سطح آزمايشكامى لـ & $\left(M_{6} Y+, Y I_{6} Y Y_{6} Y \Lambda_{6} Y 9\right)$ \\
\hline Hsa-mir-26 & PTEN & 1: أندازٔة تومور در سطح آزمايشكامقى & $\left(Y \Lambda_{6} r T_{6} \uparrow \varphi\right)$ \\
\hline Hsa-mir-30 & IkBad & 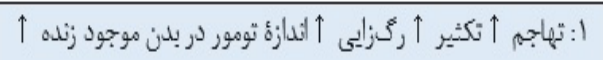 & $(₹ \varphi)$ \\
\hline Hsa-mir-92 & CTGF & 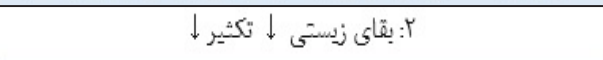 & $\left(Y+Y F_{6}, Y \Delta, Y G\right)$ \\
\hline Hsa-mir-93 & Integrin- $\beta 8 d$ & 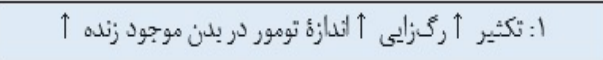 & $\left(\mid \Lambda_{6} r \cdot, r \Lambda\right)$ \\
\hline Hsa-mir-125 & Bmf & 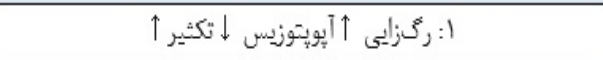 & $(\$ \varphi)$ \\
\hline Hsa-mir-146 & Notch1 & ا: تكثير لـ أدازٔة تومور در بدن موجود زئده لـ مهاجرت لـ & $(1 /, F \varphi)$ \\
\hline Hsa-mir-155 & - & 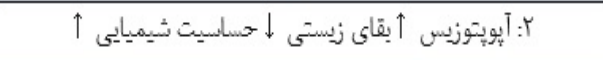 & $\left(M_{6} Y_{0}, Y_{6}, H_{6} F g\right)$ \\
\hline Hsa-mir-221 & $\begin{array}{l}\text { P27, Aktd, PUMA, } \\
\text { P57, PTP } \mu d\end{array}$ & 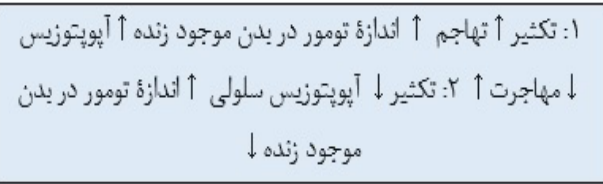 & $\left(Y Y_{G}, M_{G} F \lambda_{c} F q\right)$ \\
\hline Hsa-mir-222 & $\begin{array}{c}\text { Akt, PUMA, P57, } \\
\text { PTP } \mu \mathrm{d}\end{array}$ & 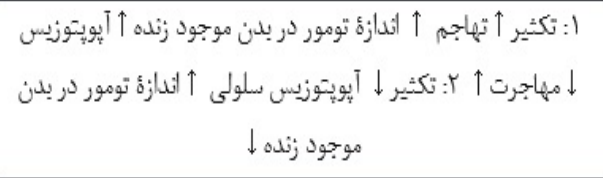 & $\left(Y r_{G}, q_{c}, F \Psi_{)}\right)$ \\
\hline Hsa-mir-335 & Daamld & 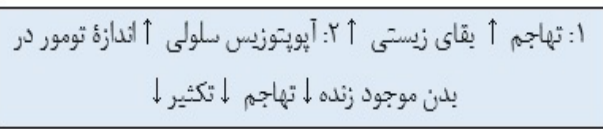 & $\left(\mp \varphi_{\Delta} \Delta^{*}\right)$ \\
\hline Hsa-mir-381 & $\mathrm{LRRC}_{4}$ & 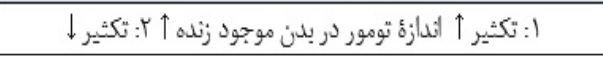 & $(\Delta 1)$ \\
\hline
\end{tabular}

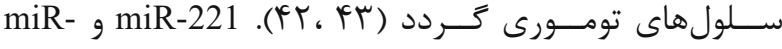

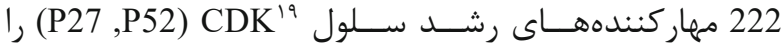

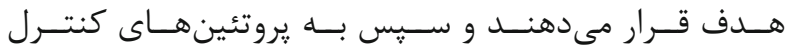

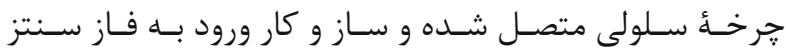

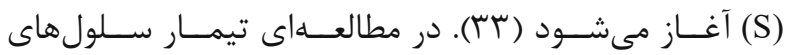

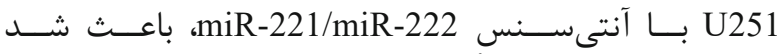

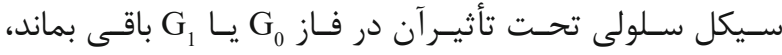

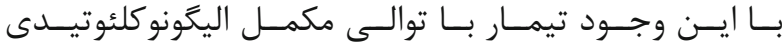

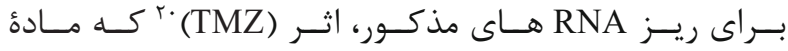

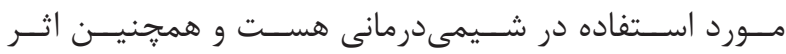

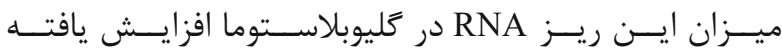

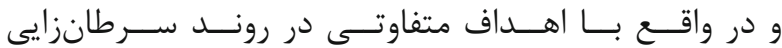

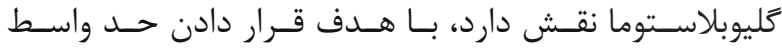

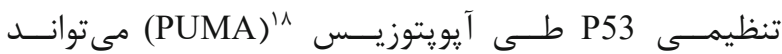

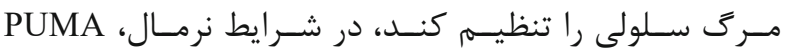

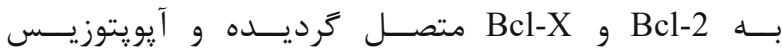

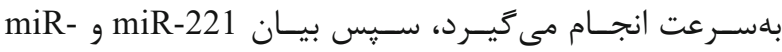

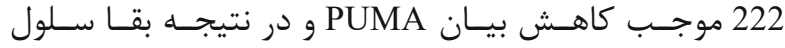

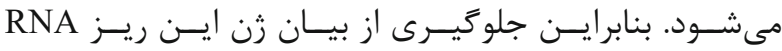

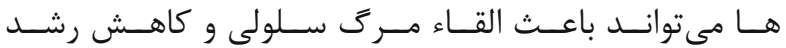

${ }^{18}$ P53-upregulated modulator of apoptosis

${ }^{19}$ Cyclin-dependent kinase

${ }^{20}$ Temozolomide 


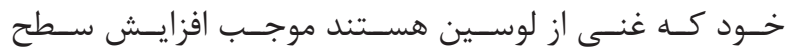

راديوترايـى را بــالا مىبــرد (צس).

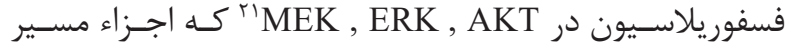

miR-335

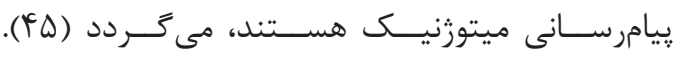

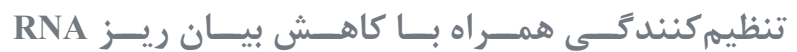

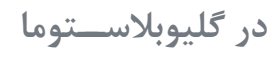

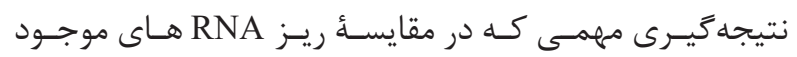

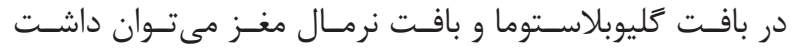

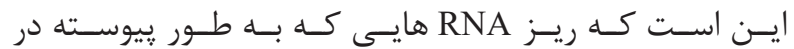

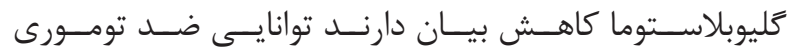

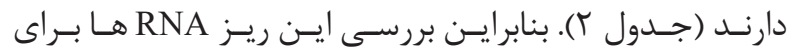

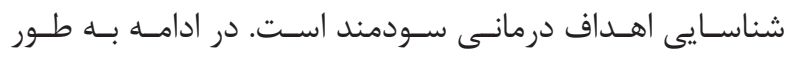

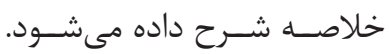

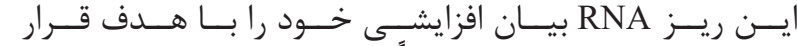

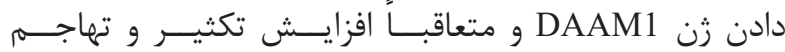

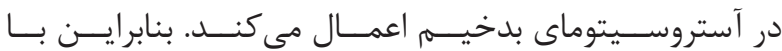

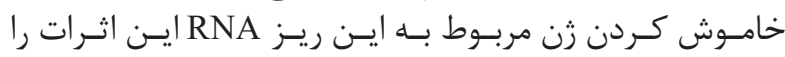

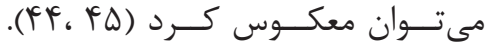
miR-381

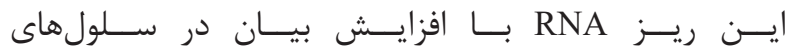

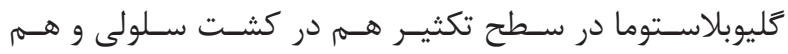

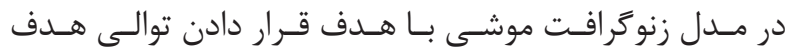

جدول r- تنظيم كنند مى همراه با كاهش بيان ريز RNA ها.

\begin{tabular}{|c|c|c|c|}
\hline RNA & هدف ثرن & تنظيمركندكى همراه با كاهش بيان ديز RNA ها & منابع \\
\hline Hsa-mir-7 & $\begin{array}{l}\text { FAK, EGFR, } \\
\quad \text { IRS } 2\end{array}$ & 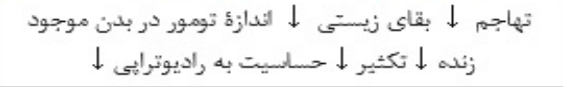 & $\left(T T, f 9,9 T_{0}, 9 \Delta_{0}, 9 \varphi\right)$ \\
\hline Hsa-mir-29 & PDPNd & تكثير \ل تهاجم لـ آيويتوزيس & $\left(T T_{0} f, . F G\right)$ \\
\hline Hsa-mir-32 & $\mathrm{Mdm} 2, \mathrm{TSC} 1$ & لا اتدازة تومور در بدن موجود زنده & $\left(1 / A_{c}+1\right)$ \\
\hline Hsa-mir-34 & $\begin{array}{l}\text { SIRT1d, c-Met, } \\
\text { Notch } 1 / 2, \\
\text { PDGFRAd, Msi1 }\end{array}$ & 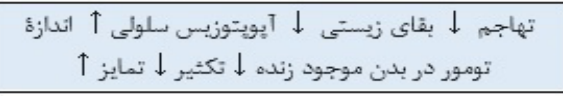 & $(\Delta 9-9 T)$ \\
\hline Hsa-mir-100 & ATM & حساسيت به راديوترايى لـ & $(\varphi \mathrm{V})$ \\
\hline Hsa-mir-101b & EZH2 Msi1 & ركتزايى لـ مهاجرت لـ بقاى زيستى لـ تكثير لـ & (9T) \\
\hline Hsa-mir- 124 & SNAI2d & تكثير ل مهاجرت ل تهاجمه لاستحكام لا & 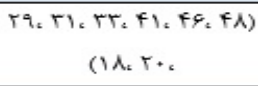 \\
\hline Hsa-mir-125 & - & $\downarrow_{10}$ ت تهاجه & $(f)$ \\
\hline Hsa-mir-128 & $\begin{array}{l}\text { WEE1, p70S6K1, } \\
\text { Msi1, E2F3a, } \\
\text { Bmi-1, EGFRd, } \\
\text { PDGFRAd }\end{array}$ & 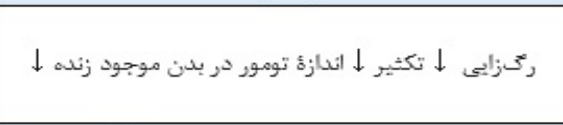 & 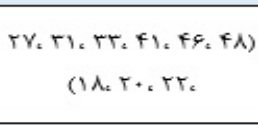 \\
\hline Hsa-mir- 135 & $\begin{array}{l}\text { STAT6, Smad5, } \\
\text { BMPR2 }\end{array}$ & 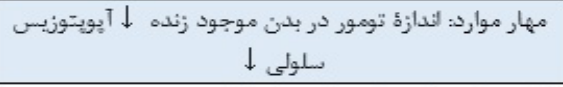 & $(\varphi \wedge)$ \\
\hline Hsa-mir- 137 & $\begin{array}{l}\text { CDK6, Msi1, } \\
\text { Cox-2 }\end{array}$ & 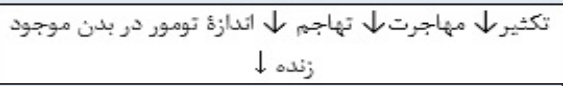 & 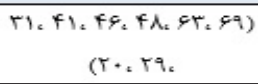 \\
\hline Hsa-mir-138 & Msil & تكثير & $\left(1 \Lambda_{c} M_{c} g T_{c} \gamma_{\cdot}\right)$ \\
\hline Hsa-mir-146b-5p & EGFR & 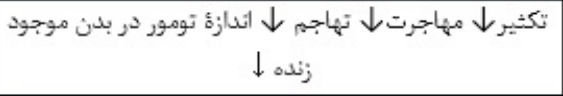 & $(v \cdot)$ \\
\hline Hsa-mir-149 & $\begin{array}{l}\text { RAP1B, Wnt- } \\
\text { pathway }\end{array}$ & تكثير ل تهاجمبم & $(T t, T H)$ \\
\hline Hsa-mir-153 & $\begin{array}{l}\text { Bcl-2, Mcl-1, Irs- } \\
2 \\
\end{array}$ & تكثير ل بقاى زيستى لآيويتوزيس سلولى † & $(\tau \cdot)$ \\
\hline Hsa-mir-181a & Bcl-2 & تكثير ل تهاججيم $\downarrow$ آيويتوزيس $\uparrow$ حساسيت به راديوترأيى & $(T V, T H)$ \\
\hline Hsa-mir-181d & Bc1-2, K-Rasd & تكثير لـ اندازؤ تومور در بدن موجود زنده لـ آيويتوزيس & $(\varphi \wedge)$ \\
\hline Hsa-mir-184 & Akt $2 d$ & تهاجمم \لآبويتوزيس & $(\mathrm{r})$ \\
\hline Hsa-mir-185 & DNMT1 & لمتيالاسيون DNA & $(\varphi 9)$ \\
\hline Hsa-mir-218 & IKK- $\beta \mathrm{d}$ & $\downarrow$ تهاجمr & $\left(1 \Lambda_{2} r_{c} f 9\right)$ \\
\hline Hsa-mir-326bc & $\begin{array}{l}\text { Notch-1/2, } \\
\text { PKM2d }\end{array}$ & 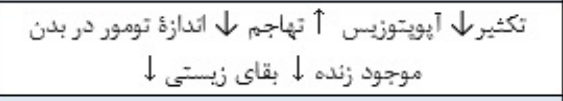 & $\left(\varphi V_{,}, V_{1}\right)$ \\
\hline Hsa-mir-483-5pb & ERK1d & تكثير & $(11)$ \\
\hline Hsa-mir-491-5pb & MMP9d & تهاجميم تهاجم & (TT) \\
\hline
\end{tabular}

${ }^{21}$ Extracellolar signal-regulated kinases 


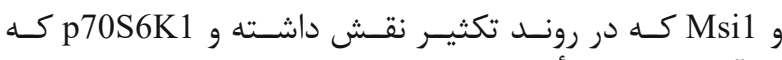

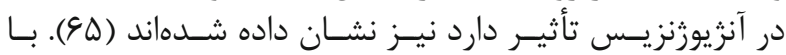

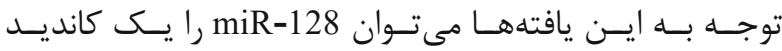

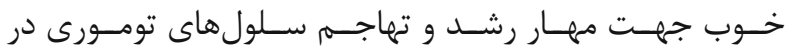

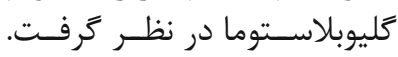

miR-137

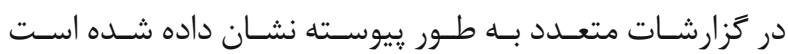

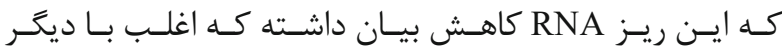

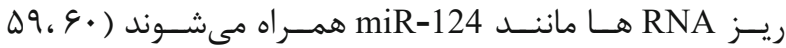

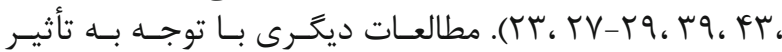

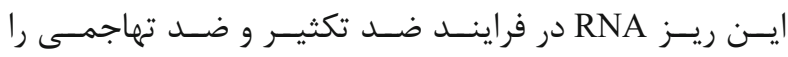

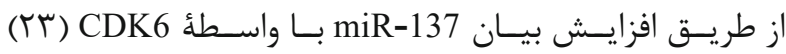

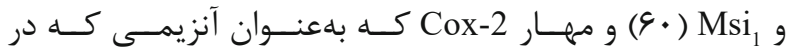

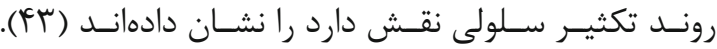

$$
\text { نتيجه كيرى رون }
$$

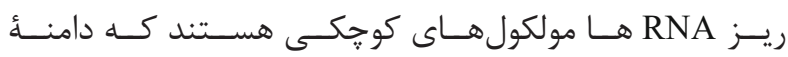

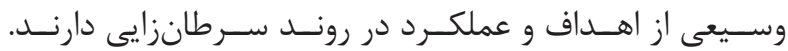

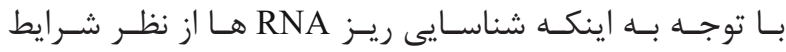

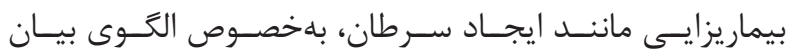

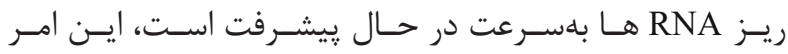

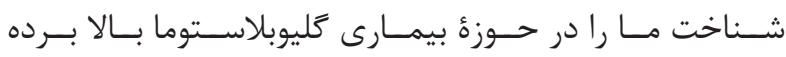

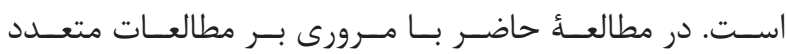

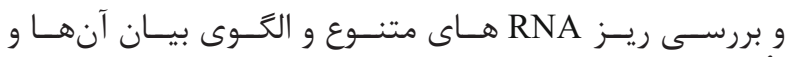

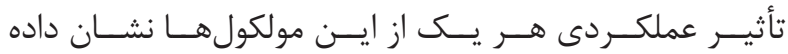

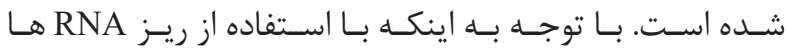

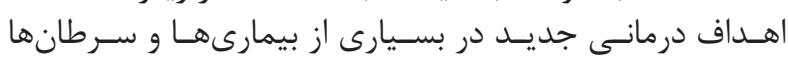

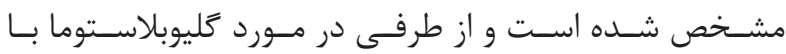

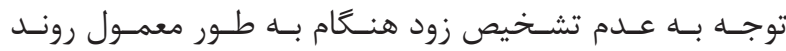

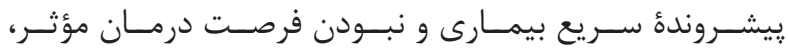

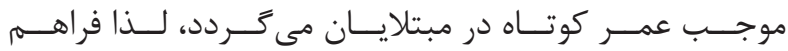

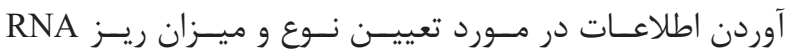

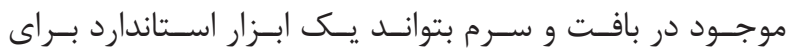

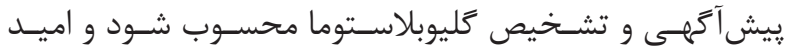

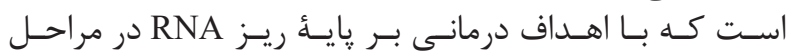

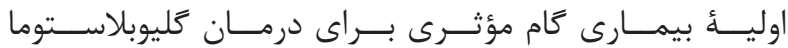

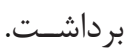

miR-7

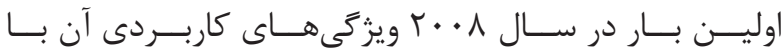

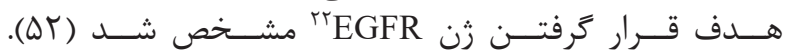

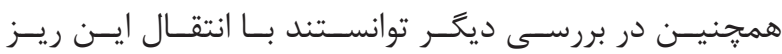

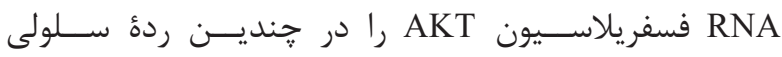

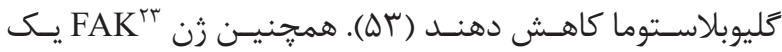

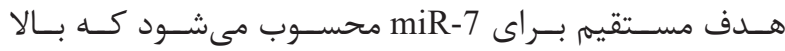

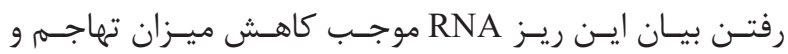

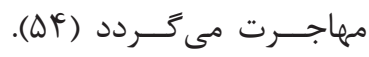
miR-34

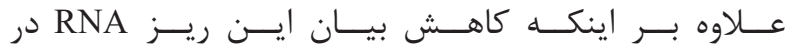

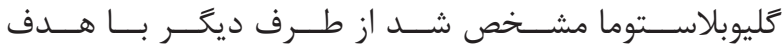

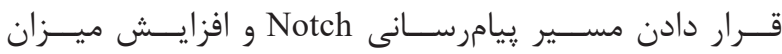

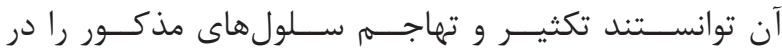

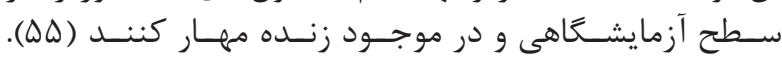

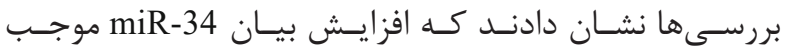

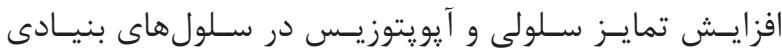

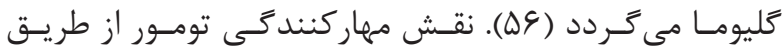

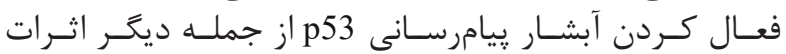

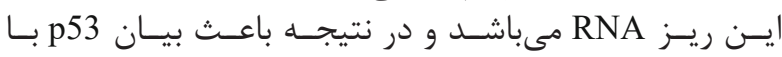

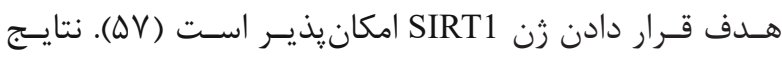

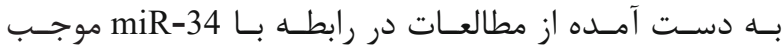

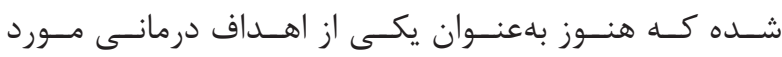

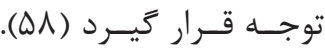

miR-128

در مطالعـات متعـددى مهــار miR-128 را در ردهـــــا و

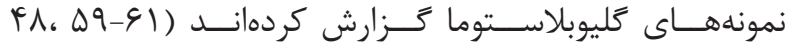

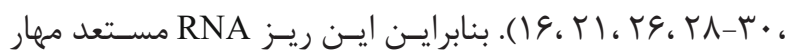

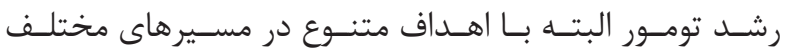

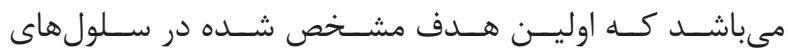

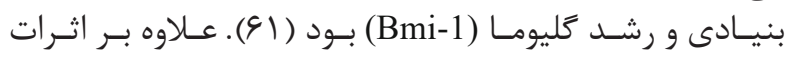

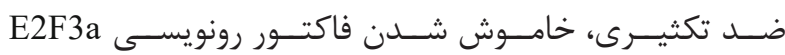

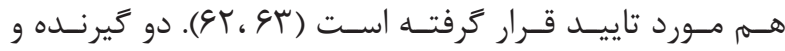

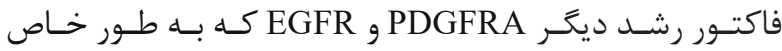

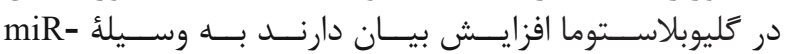

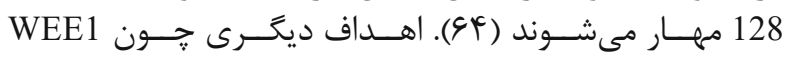


1. Ahir BK, Ozer H, Engelhard HH, Lakka SS. MicroRNAs in glioblastoma pathogenesis and therapy: A comprehensive review. Crit Rev Oncol Hematol. 2017; 120: 22-33.

2. Sathipati SY, Huang H-L, Ho S-Y. Estimating survival time of patients with glioblastoma multiforme and characterization of the identified microRNA signatures. BMC Genomics. 2016; 17(13): 1022. doi: 10.1186/ s12864-016-3321-y.

3. Bartel DP. MicroRNAs: target recognition and regulatory functions. Cell. 2009; 136(2): 215-33.

4. Kusenda B, Mraz M, Mayer J, Pospisilova S. MicroRNA biogenesis, functionality and cancer relevance. Biomed Pap Med Fac Univ Palacky Olomouc Czech Repub. 2006; 150(2): 205-15.

5. Shea A, Harish V, Afzal Z, Chijioke J, Kedir H, Dusmatova S, et al. MicroRNAs in glioblastoma multiforme pathogenesis and therapeutics. Cancer Med. 2016; 5(8): 1917-46.

6. Henriksen M, Johnsen KB, Andersen HH, Pilgaard L, Duroux M. MicroRNA expression signatures determine prognosis and survival in glioblastoma multiforme-a systematic overview. Mol Neurobiol. 2014; 50(3): 896-913.

7. Svoronos AA, Engelman DM, Slack FJ. OncomiR or tumor suppressor? The duplicity of microRNAs in cancer. Cancer Res. 2016; 76(13): 3666-70.

8. Qu Y, Zhang H, Sun W, Han Y, Li S, Qu Y, et al. Micro RNA-155 promotes gastric cancer growth and invasion by negatively regulating transforming growth factor- $\beta$ receptor 2. Cancer Sci. 2018; 109(3): 618-28.

9. Zhu Y, Gu J, Li Y, Peng C, Shi M, Wang X, et al. MiR-17-5p enhances pancreatic cancer proliferation by altering cell cycle profiles via disruption of RBL2/E2F4repressing complexes. Cancer Lett. 2018; 412: 59-68.

10. Liu L, Ren W, Chen K. MiR-34a promotes apoptosis and inhibits autophagy by targeting HMGB1 in acute myeloid leukemia cells. Cell Physiol Biochem. 2017; 41(5): 1981-92.

11. Li GC, Cao XY, Li YN, Qiu YY, Li YN, Liu XJ, et al. MicroRNA-374b inhibits cervical cancer cell proliferation and induces apoptosis through the p38/ ERK signaling pathway by binding to JAM-2. J Cell Physiol. 2018; 233(9): 7379-90.

12. Saliminejad K, Khorram Khorshid HR, Soleymani
منابع

Fard S, Ghaffari SH. An overview of microRNAs: biology, functions, therapeutics, and analysis methods. J Cell Physiol. 2019; 234(5): 5451-65.

13. Malzkorn B, Wolter M, Liesenberg F, Grzendowski M, Stühler K, Meyer HE, et al. Identification and functional characterization of microRNAs involved in the malignant progression of gliomas. Brain Pathol. 2010; 20(3): 539-50.

14. Jiang L, Mao P, Song L, Wu J, Huang J, Lin C, et al. miR-182 as a prognostic marker for glioma progression and patient survival. Am J Pathol. 2010; 177(1): 29-38.

15. Sun G, Cao Y, Shi L, Sun L, Wang Y, Chen C, et al. Overexpressed miRNA-137 inhibits human glioma cells growth by targeting Rac1. Cancer Biother Radiopharm. 2013; 28(4): 327-34.

16. Lages E, Guttin A, El Atifi M, Ramus C, Ipas H, Dupré I, et al. MicroRNA and target protein patterns reveal physiopathological features of glioma subtypes. PloS One. 2011; 6(5): e20600.

17. Schraivogel D, Weinmann L, Beier D, Tabatabai G, Eichner A, Zhu JY, et al. CAMTA1 is a novel tumour suppressor regulated by miR-9/9* in glioblastoma stem cells. EMBO J. 2011; 30(20): 4309-22.

18. Dews M, Fox JL, Hultine S, Sundaram P, Wang W, Liu YY, et al. The myc-mir-17-92 axis blunts TGF $\beta$ signaling and production of multiple TGF $\beta$-dependent antiangiogenic factors. Cancer Res. 2010; 70(20): 8233-46.

19. Ernst A, Campos B, Meier J, Devens F, Liesenberg F, Wolter M, et al. De-repression of CTGF via the miR17-92 cluster upon differentiation of human glioblastoma spheroid cultures. Oncogene. 2010; 29(23): 3411-22.

20. Chan JA, Krichevsky AM, Kosik KS. MicroRNA-21 is an antiapoptotic factor in human glioblastoma cells. Cancer Res. 2005; 65(14): 6029-33.

21. Ciafre S, Galardi S, Mangiola A, Ferracin M, Liu C-G, Sabatino G, et al. Extensive modulation of a set of microRNAs in primary glioblastoma. Biochem Biophys Res Commun. 2005; 334(4): 1351-8.

22. Huse JT, Brennan C, Hambardzumyan D, Wee B, Pena J, Rouhanifard SH, et al. The PTEN-regulating microRNA miR-26a is amplified in high-grade glioma and facilitates gliomagenesis in vivo. Genes Dev. 2009; 23(11): 1327-37.

23. Silber J, Lim DA, Petritsch C, Persson AI, Maunakea 


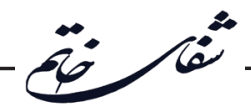

$\mathrm{AK}, \mathrm{Yu} \mathrm{M}$, et al. miR-124 and miR-137 inhibit proliferation of glioblastoma multiforme cells and induce differentiation of brain tumor stem cells. BMC Med. 2008; 6(1): 14. doi: 10.1186/1741-7015-6-14.

24. Sasayama T, Nishihara M, Kondoh T, Hosoda $\mathrm{K}$, Kohmura E. MicroRNA-10b is overexpressed in malignant glioma and associated with tumor invasive factors, uPAR and RhoC. Int J Cancer. 2009; 125(6): 1407-13.

25. Sun L, Yan W, Wang Y, Sun G, Luo H, Zhang J, et al. MicroRNA-10b induces glioma cell invasion by modulating MMP-14 and UPAR expression via HOXD10. Brain Res. 2011; 1389: 9-18.

26. Rao SA, Santosh V, Somasundaram K. Genomewide expression profiling identifies deregulated miRNAs in malignant astrocytoma. Modern Pathology. 2010; 23(10): 1404-17.

27. Wuchty S, Arjona D, Li A, Kotliarov Y, Walling $\mathrm{J}$, Ahn S, et al. Prediction of associations between microRNAs and gene expression in glioma biology. PloS One. 2011; 6(2): e14681.

28. Lavon I, Zrihan D, Granit A, Einstein O, Fainstein $\mathrm{N}$, Cohen MA, et al. Gliomas display a microRNA expression profile reminiscent of neural precursor cells. Neuro Oncol. 2010; 12(5): 422-33.

29. Zhou X, Ren Y, Moore L, Mei M, You Y, Xu P, et al. Downregulation of miR-21 inhibits EGFR pathway and suppresses the growth of human glioblastoma cells independent of PTEN status. Lab Invest. 2010; 90(2): 144-55.

30. Lakomy R, Sana J, Hankeova S, Fadrus P, Kren L, Lzicarova E, et al. MiR-195, miR-196b, miR-181c, miR-21 expression levels and O-6-methylguanine-DNA methyltransferase methylation status are associated with clinical outcome in glioblastoma patients. Cancer Sci. 2011; 102(12): 2186-90.

31. Dong H, Luo L, Hong S, Siu H, Xiao Y, Jin L, et al. Integrated analysis of mutations, miRNA and mRNA expression in glioblastoma. BMC Syst Biol. 2010; 4(1): 163. doi: 10.1186/1752-0509-4-163.

32. Kwak H, Kim Y, Chun K, Woo Y, Park S, Jeong $\mathrm{J}$, et al. Downregulation of Spry2 by miR-21 triggers malignancy in human gliomas. Oncogene. 2011; 30(21): 2433-42.

33. Li Y, Li W, Yang Y, Lu Y, He C, Hu G, et al. MicroRNA-21 targets LRRFIP1 and contributes to VM26 resistance in glioblastoma multiforme. Brain Res.
2009; 1286: 13-8.

34. Zhou X, Zhang J, Jia Q, Ren Y, Wang Y, Shi L, et al. Reduction of miR-21 induces glioma cell apoptosis via activating caspase 9 and 3. Oncol Rep. 2010; 24(1): 195-201.

35. Papagiannakopoulos T, Shapiro A, Kosik KS. MicroRNA-21 targets a network of key tumorsuppressive pathways in glioblastoma cells. Cancer Res. 2008; 68(19): 8164-72.

36. Gaur AB, Holbeck SL, Colburn NH, Israel MA. DownregulationofPdcd4bymir-21 facilitatesglioblastoma proliferation in vivo. Neuro Oncol. 2011; 13(6): 580-90.

37. Gabriely G, Wurdinger T, Kesari S, Esau CC, Burchard J, Linsley PS, et al. MicroRNA 21 promotes glioma invasion by targeting matrix metalloproteinase regulators. Mol Cell Biol. 2008; 28(17): 5369-80.

38. Li Y, Zhao S, Zhen Y, Li Q, Teng L, Asai A, et al. A miR-21 inhibitor enhances apoptosis and reduces G 2-M accumulation induced by ionizing radiation in human glioblastoma U251 cells. Brain Tumor Pathol. 2011; 28(3): 209-14.

39. Zhi F, Chen X, Wang S, Xia X, Shi Y, Guan W, et al. The use of hsa-miR-21, hsa-miR-181b and hsa-miR106 a as prognostic indicators of astrocytoma. Eur J Cancer. 2010; 46(9): 1640-9.

40. Ren Y, Zhou X, Mei M, Yuan X-B, Han L, Wang G-X, et al. MicroRNA-21 inhibitor sensitizes human glioblastoma cells U251 (PTEN-mutant) and LN229 (PTEN-wild type) to taxol. BMC Cancer. 2010; 10(1): 27. doi: 10.1186/1471-2407-10-27.

41. Ren Y, Kang C-S, Yuan X-B, Zhou X, Xu P, Han L, et al. Co-delivery of as-miR-21 and 5-FU by poly (amidoamine) dendrimer attenuates human glioma cell growth in vitro. J Biomater Sci Polym Ed. 2010; 21(3): 303-14.

42. Zhang C-Z, Zhang J-X, Zhang A-L, Shi Z-D, Han L, Jia Z-F, et al. MiR-221 and miR-222 target PUMA to induce cell survival in glioblastoma. Mol Cancer. 2010; 9(1): 229. doi: 10.1186/1476-4598-9-229.

43. Chen L, Zhang J, Han L, Zhang A, Zhang C, Zheng Y, et al. Downregulation ofmiR-221/222 sensitizes glioma cells to temozolomide by regulating apoptosis independently of p53 status. Oncol Rep. 2012; 27(3): 854-60.

44. Shu M, Zheng X, Wu S, Lu H, Leng T, Zhu W, et al. Targeting oncogenic miR-335 inhibits growth and invasion of malignant astrocytoma cells. Mol Cancer. 
2011; 10(1): 59. doi: 10.1186/1476-4598-10-59.

45. Tang H, Liu X, Wang Z, She X, Zeng X, Deng M, et al. Interaction of hsa-miR-381 and glioma suppressor LRRC4 is involved in glioma growth. Brain Res. 2011; 1390: 21-32.

46. Ernst A, Campos B, Meier J, Devens F, Liesenberg F, Wolter M, et al. De-repression of CTGF via the miR-1792 cluster upon differentiation of human glioblastoma spheroid cultures. Oncogene. 2010; 29(23): 3411-22.

47. Chaudhry MA, Sachdeva H, Omaruddin RA. Radiation-induced micro-RNA modulation in glioblastoma cells differing in DNA-repair pathways. DNA Cell Biol. 2010; 29(9): 553-61.

48. Li D, Chen P, Li X-Y, Zhang L-Y, Xiong W, Zhou M, et al. Grade-specific expression profiles of miRNAs/mRNAs and docking study in human grade I-III astrocytomas. OMICS. 2011; 15(10): 673-82.

49. Schramedei K, Mörbt N, Pfeifer G, Läuter J, Rosolowski M, Tomm J, et al. MicroRNA-21 targets tumor suppressor genes ANP32A and SMARCA4. Oncogene. 2011; 30(26): 2975-85.

50. Guan Y, Mizoguchi M, Yoshimoto K, Hata N, Shono T, Suzuki SO, et al. MiRNA-196 is upregulated in glioblastoma but not in anaplastic astrocytoma and has prognostic significance. Clin Cancer Res. 2010; 16(16): 4289-97.

51. Conti A, Aguennouz MH, La Torre D, Tomasello C, Cardali S, Angileri FF, et al. miR-21 and 221 upregulation and miR-181b downregulation in human grade II-IV astrocytic tumors. J Neurooncol. 2009; 93(3): 325-32.

52. Parsons DW, Jones S, Zhang X, Lin JC-H, Leary $\mathrm{RJ}$, Angenendt $\mathrm{P}$, et al. An integrated genomic analysis of human glioblastoma multiforme. Science. 2008; 321(5897): 1807-12.

53. Kefas B, Godlewski J, Comeau L, Li Y, Abounader $\mathrm{R}$, Hawkinson $\mathrm{M}$, et al. microRNA-7 inhibits the epidermal growth factor receptor and the Akt pathway and is down-regulated in glioblastoma. Cancer Res. 2008; 68(10): 3566-72.

54. WU D-g, Wang Y-y, Fan L-g, Hui L, Bin H, Sun L-h, et al. MicroRNA-7 regulates glioblastoma cell invasion via targeting focal adhesion kinase expression. Chin Med J (Engl). 2011; 124(17): 2616-21.

55. Li Y, Guessous F, Zhang Y, DiPierro C, Kefas B, Johnson E, et al. MicroRNA-34a inhibits glioblastoma growth by targeting multiple oncogenes. Cancer Res.
2009; 69(19): 7569-76.

56. Guessous F, Zhang Y, Kofman A, Catania A, Li Y, Schiff D, et al. microRNA-34a is tumor suppressive in brain tumors and glioma stem cells. Cell Cycle. 2010; 9(6): 1031-6.

57. Luan S, Sun L, Huang F. MicroRNA-34a: a novel tumor suppressor in p53-mutant glioma cell line U251. Arch Med Res. 2010; 41(2): 67-74.

58. Silber J, Jacobsen A, Ozawa T, Harinath G, Pedraza A, Sander C, et al. miR-34a repression in proneural malignant gliomas upregulates expression of its target PDGFRA and promotes tumorigenesis. PloS One. 2012; 7(3): e33844.

59. Zhang C, Han L, Zhang A, Yang W, Zhou X, Pu $\mathrm{P}$, et al. Global changes of mRNA expression reveals an increased activity of the interferon-induced signal transducer and activator of transcription (STAT) pathway by repression of miR-221/222 in glioblastoma U251 cells. Int J Oncol. 2010; 36(6): 1503-12.

60. Vo DT, Qiao M, Smith AD, Burns SC, Brenner AJ, Penalva LO. The oncogenic RNA-binding protein Musashi1 is regulated by tumor suppressor miRNAs. RNA Biol. 2011; 8(5): 817-28.

61. Godlewski J, Nowicki MO, Bronisz A, Williams S, Otsuki A, Nuovo G, et al. Targeting of the Bmi-1 oncogene/stem cell renewal factor by microRNA-128 inhibits glioma proliferation and self-renewal. Cancer Res. 2008; 68(22): 9125-30.

62. Cui J, Zhao Y, Sethi P, Li Y, Mahta A, Culicchia F, et al. Micro-RNA-128 (miRNA-128) down-regulation in glioblastoma targets ARP5 (ANGPTL6), Bmi-1 and E2F-3a, key regulators of brain cell proliferation. J Neurooncol. 2010; 98(3): 297-304.

63. Zhang Y, Chao T, Li R, Liu W, Chen Y, Yan X, et al. MicroRNA-128 inhibits glioma cells proliferation by targeting transcription factor E2F3a. J Mol Med (Berl). 2009; 87(1): 43-51.

64. Papagiannakopoulos T, Friedmann-Morvinski D, Neveu P, Dugas J, Gill R, Huillard E, et al. Pro-neural miR-128 is a glioma tumor suppressor that targets mitogenic kinases. Oncogene. 2012; 31(15): 1884.

65. Shi Z-m, Wang J, Yan Z, You Y-p, Li C-y, Qian X, et al. MiR-128 inhibits tumor growth and angiogenesis by targeting p70S6K1. PloS One. 2012; 7(3): e32709.

66. Zhang Z, Tang H, Wang Z, Zhang B, Liu W, Lu H, et al. MiR-185 targets the DNA methyltransferases 1 and regulates global DNA methylation in human glioma. 
Molecular Cancer. 2011; 10(1): 124.

67. Kefas B, Comeau L, Floyd D, Seleverstov O, Godlewski J, Schmittgen T, et al. diPierro CG, Li Y, Chiocca EA, Lee J, Fine H, Abounader R, Lawler S, Purow B. The neuronal microRNA miR-326 acts in a feedback loop with notch and has ther-apeutic potential against brain tumors. J Neurosci. 2009; 29: 15161-8.

68. Wang X-F, Shi Z-M, Wang X-R, Cao L, Wang Y-Y, Zhang J-X, et al. MiR-181d acts as a tumor suppressor in glioma by targeting K-ras and Bcl-2. J Cancer Res Clin Oncol. 2012; 138(4): 573-84.
69. Ng WL, Yan D, Zhang X, Mo Y-Y, Wang Y. Overexpression of miR-100 is responsible for the lowexpression of ATM in the human glioma cell line: M059J. DNA Repair (Amst). 2010; 9(11): 1170-5.

70. Katakowski M, Zheng X, Jiang F, Rogers T, Szalad A, Chopp M. MiR-146b-5p suppresses EGFR expression and reduces in vitro migration and invasion of glioma. Cancer Invest. 2010; 28(10): 1024-3.

71. Kefas B, Comeau L, Erdle N, Montgomery E, Amos S, Purow B. Pyruvate kinase M2 is a target of the tumorsuppressive microRNA-326 and regulates the survival of glioma cells. Neuro Oncol. 2010; 12(11): 1102-12. 